\title{
The Cognitive Prominence of Euphemism Production: A Perspective of the Embodied-Cognitive Approach
}

\author{
Deyin Long ${ }^{1}$ \\ ${ }^{1}$ School of Foreign Languages, Sichuan University of Arts and Science, Dazhou, Sichuan Province, China \\ Correspondence: Deyin Long, School of Foreign Languages, Sichuan University of Arts and Science, Dazhou, \\ 635000, Sichuan Province, China. E-mail: daniellong2005@sina.com
}

Received: August 15, 2020

Accepted: September 18, 2020

Online Published: September 26, 2020

doi:10.5539/ijel.v10n6p279

URL: https://doi.org/10.5539/ijel.v10n6p279

\begin{abstract}
The previous research on euphemism is mainly conducted from the perspectives of traditional linguistics, sociolinguistics, pragmatics, cognitive linguistics, and the philosophy of mind, but few studies focus on the cognitive prominence of euphemism production from the perspective of the embodied-cognitive approach. This paper takes the euphemisms in English literary works as the corpora and explores the cognitive prominence of euphemism production from the perspective of the embodied-cognitive approach to reveal the production mechanism of euphemism. It is found that euphemism production highlights the linguistic subject's embodied cognition of identity, causal implication, and supervenience with reality. The linguistic subject's embodied cognition of identity with reality explains that euphemism is in place of the common expression to direct at an unpleasant or embarrassing thing or event in reality because euphemism is identical to common expression. The linguistic subject's embodied cognition of causal implication with reality accounts for the fact that the interaction between the mental and the physical follows the principle of causal interaction. Common expression causally implicates euphemism and the causal implication between them is restricted by the specific context and the linguistic subject's intentionality. The linguistic subject's embodied cognition of supervenience with reality indicates that the consciousness of the linguistic subject towards the described thing or event supervenes globally on its physical property. Euphemism production is the result of the linguistic subject's embodied cognition with reality. Cognitive prominence from the perspective of the embodied-cognitive approach has very strong explanatory power over the production mechanism of linguistic expressions.
\end{abstract}

Keywords: cognitive prominence, euphemism production, the embodied-cognitive approach, embodied cognition

\section{Introduction}

Language, an important carrier of thought, is the mental representation of realistic existence. Euphemism is a common linguistic phenomenon in English, Chinese, and many other languages. It is also one of the topics that academic circles continually pay attention to. Euphemism is defined in the second edition of The Oxford Dictionary of Phrase and Fable (2006) as "a mild or indirect word or expression substituted for one considered to be too harsh or blunt when referring to something unpleasant or embarrassing." For instance, "pass away" is a euphemism for "die" and "pass water" is a euphemism of "urinate". Euphemism can be divided into traditional euphemism and stylistic euphemism according to whether the described object is taboo or not (Liu, 2002). Traditional euphemism is closely related to taboo, and the expression that indirectly describes the unpleasant or embarrassing thing or event is a euphemism. Classic taboo examples include death, vulgarity, sex, religion, and politics. Stylistic euphemism has little to do with taboo. It is the linguistic expression used by speakers to express politeness, avoid stimulation, or win over the cooperation from the other side. It often replaces the unpleasant or embarrassing expressions with praise. Whether it is a traditional euphemism or a stylistic euphemism, the essence is to replace direct or unpleasant words or phrases with indirect, tactful ones. In this paper, both traditional euphemism and stylistic euphemism are referred to as euphemism, while more accurate and direct words or phrases are called common expressions.

Euphemism, which belongs to metaphorical utterance, is a skillful linguistic expression with substitution as its inherent nature. Substitution is a nature derived from the linguistic subject to the actual existence of language symbols and euphemism production takes on the substitution nature. For example: 
(1) When we came back, we found him in his armchair, peacefully gone to bed-but forever. (Frederick Engels, Speech at the Graveside of Karl Marx)

In (1), "gone to bed-but forever" is a euphemistic expression, which substitutes for the common expression "died". Both the euphemism and the common expression refer to the same unpleasant event "come to the end of one's life".

From the example, we can see that euphemism is mostly tactful and indirect, while the replaced common expression is stiff or direct, and there are differences between euphemism and common expression both in forms and meanings. Euphemism production takes on the nature of substitution for common expression and thus some figures or profiles are salient in euphemism production. But what figures or profiles are prominent in euphemism production? This is exactly the question that this paper intends to answer. This paper takes the euphemisms in English literary works as the corpora and explores the cognitive prominence of euphemism production from the perspective of the embodied-cognitive approach to reveal the production mechanism of euphemism.

\section{Literature Review}

The research on euphemism has a long history. Scholars have made in-depth analyses and discussions of euphemism from different perspectives. In general, the previous study of euphemism is mainly conducted in five aspects. The first aspect is the study of euphemism from traditional linguistics. The research in this field mainly focuses on the definition, formation, or rhetorical effect of euphemism from a diachronic perspective (Linfoot-Ham, 2005). The second aspect is the study of euphemism from sociolinguistics. Scholars in this discipline analyze the cultural connotations and socio-cultural functions of different euphemisms from the perspective of sociolinguistics $(\mathrm{Li}, 2002)$. The third aspect is the study of euphemism from pragmatics. Scholars in this field stress the use of euphemism and its comparative study, such as the use of English words as euphemisms in Spanish fashion (Diez-Arroyo, 2016). The fourth is the study of euphemism from cognitive linguistics. The research in this field mainly uses the related cognitive theories such as intentionality to explain the meaning construction or the production mechanism of euphemism $(\mathrm{Li}, 2016)$. The fifth aspect is the study of euphemism from the philosophy of mind. The research field reveals the mechanism of euphemism production by exploring the laws of mental activities related to language knowledge hidden behind euphemism (Liu, 2013; Xu, 2015).

The above studies reveal the use mechanism of euphemism from different angles and enrich the study of euphemism to a great extent, but few studies pay attention to the cognitive prominence of euphemism production from the perspective of the embodied-cognitive approach. The approach carries profound philosophical implications that play a key role in revealing the body-mind motivation of language via the relationship between existence and thought (Wang, 2019), and this is the reason why this paper takes the perspective of the embodied-cognitive approach to the cognitive prominence of euphemism production.

\section{Cognitive Prominence and the Embodied-Cognitive Approach}

\subsection{Cognitive Prominence}

Cognition is about the knowledge and experience of things or events, including a series of mental activities, such as feeling, memory, thought, judgment, inference, and imagination. Individual differences in education, culture, talent, beliefs, values, and so on lead to certain differences in people's cognition of the same thing or event. The concept of cognitive prominence in cognitive linguistics includes a series of technical terms, such as salience or prominence, foregrounding, highlighting, and profiling. Salience or prominence refers to the choice and arrangement of the information conveyed by language (Ungerer \& Schmid, 2001, p. 38). The foreground and background are two important elements that make up a figure-ground alignment; the former refers to the focus of attention, while the latter provides the setting to highlight the foreground. Highlighting means that people tend to focus on only one aspect of something and ignore its other aspects when getting to know it. Profiling, a cognitive grammar mechanism, is prominence or salience. It is essentially the same as the figure-ground perceptual model in Gestalt psychology (Wang \& Liu, 2020). Cognitive profiling can be used for semantic structure analysis. The semantic pole of a linguistic expression is equivalent to a semantic structure and the description of the semantic pole depends on profile and base. The semantic value of the linguistic expression does not reside in the profile, nor the base, but in the combination of the profile and the base (Langacker, 2004, p. 183). The profile is the entity designated by the semantic structure. In the course of recognizing the semantic structure, the profile of the structure is usually foregrounded and thus it becomes the focus of attention. The base, "the cognitive structure against which the designatum of the semantic structure is profiled" (Langacker, 2004, p. 486), is the foundation of semantic formation and understanding, and it is often hidden in the background. 
Cognitive prominence is an important theory to construe linguistic expressions. Another concept that is related to cognitive prominence is the cognitive domain, a knowledge network that provides context and background knowledge for the semantic structure of the linguistic expression and influences its semantic structure. There are some differences between the cognitive domain and the base. The base is the inherent and intrinsic conceptual content activated by the linguistic expression, providing more direct, specific, and relevant conceptual information for the semantic structures of language units, while the cognitive domain is the broader background knowledge on which the formation of semantic structures depends.

\subsection{The Embodied-Cognitive Approach}

The embodied-cognitive approach is put forward based on cognitive linguistics and can be described as follows: reality - cognition - language (Wang, 2006, p. 6). It is considered to be the core approach of embodied-cognitive linguistics (Wang, 2014), a new discipline developed based on cognitive linguistics (Peng, 2019). It holds that language and reality are not directly related. Instead, language needs to build connections with reality through cognition. Language originates from the linguistic subject's interactive experience and cognitive processing with reality. On the one hand, reality determines cognition, and cognition determines language; on the other hand, language influences cognition, and cognition influences reality (Lei, 2019; Wang, 2019). Cognition is just the mental representation of the described thing or event.

The embodied-cognitive approach is a new one to the production mechanism of linguistic expression. The production of linguistic expression involves the experience of the realistic existence and the cognition of the linguistic subject. When the linguistic subject produces linguistic expression, his embodied cognition is involved in the face of the described thing or event. In the end, the common expression may be replaced by other linguistic expressions and the linguistic subject's embodied cognition is prominent, so approaching from the perspective of the embodied-cognitive approach is the key to the study of the cognitive prominence of linguistic expression production.

\section{Euphemism, Common Expression, and Euphemism Production}

Euphemism and common expression are in the same cognitive domain. The meaning expressed by euphemism is specifically and potentially relevant to the one expressed by common expression. Both euphemism and common expression direct at the same unpleasant or embarrassing thing or event and they have the same ground or base, i.e., the embarrassing or unpleasant thing or event. However, common expression and euphemism highlight different figures or profiles, so their semantic structures are different. For example:

(2) The defeated are not hidden away somewhere else on the wrong side of town. (Thomas Griffith, Loving and Hating New York)

In (2), "on the wrong side of town" is a euphemistic expression, referring to "in the poor or miserable areas of town". The common expression like "in the slums or ghettoes of town" represents such images as poverty and seeking shelter, but it directs at the same areas as the euphemistic expression "on the wrong side of town". The euphemistic expression avoids direct or unpleasant images and highlights the linguistic subject's cognition of the areas ("wrong"), while the common expression highlights the linguistic subject's experience of the areas. Therefore, the semantic structures of the euphemistic expression and those of the common ones are different. Euphemism production highlights different figures or profiles.

\section{The Cognitive Prominence of Euphemism Production from the Perspective of the Embodied-Cognitive Approach}

In the process of euphemism production, the experience of the described thing or event in reality may activate the cognition of the linguistic subject, such as identity, causal implication, and supervenience (Xu, 2015, 2016). Based on cognitive prominence from the perspective of the embodied-cognitive approach, the linguistic subject's embodied cognition may come to the front stage and become the focus of attention, and thus euphemism production highlights the linguistic subject's embodied cognition of identity, causal implication, and supervenience with reality.

\subsection{The Embodied Cognition of Identity}

The reason why euphemism can replace common expression to direct at the unpleasant or embarrassing thing or event is that euphemism and common expression are identical. Common expression reflects the experience of the described thing or event, while euphemism represents the linguistic subject's cognition of the thing or event. Identity is a principle of great concern in philosophy, logic, and psychology. Philosophy and logic focus on the metaphysical problem of identity and psychology pays more attention to how identity is formed in the mind. The identity in language use is about the relationship between two levels of thought and language. It refers to what is 
separated on one level of thought and language, and what is combined on the other level of thought and language. In certain contexts, the identical things in an identical statement can be replaced by each other. So, what kind of things are identical? The Principle of Identity of Indiscernibles proposed by Leibniz (1969, p. 309) can answer the question. The theme of the principle is: if any individual $\mathrm{x}$ and $\mathrm{y}$ are considered indiscernible, they can be regarded as identical, equivalent, and replaceable. That is to say, two or more identical things are indistinguishable and can be replaced by each other in certain contexts.

The identity in language use can be described as the generalization made by the linguistic subject of two (or more) things that appear to be different according to their knowledge and the characteristics of common ground in one aspect. Two (or more) things that appear to be different constitute an identical statement. What the identical statement expresses is a cognitive relationship based on the identity of the objective things. The identity of objective things itself refers to the persistence, stability, and certainty of objective things in a certain temporal-spatial range. What the identical statement expresses is a three-level relationship. The linguistic expression has levels of form, meaning, and reference, which combine to form the two basic and common situations of identical statements: the one with different forms and meanings, but the same reference, and the other with different forms, but the same meaning and reference. The former means that the form and meaning (connotation) of words judged to be identical are different, but the reference (extension) is the same, while the latter means that identical words have different forms, but the meaning (connotation) and the reference (extension) are the same.

Euphemism can replace common expression to direct at the unpleasant or embarrassing object because they are identical. The mind of the linguistic subject pays attention to and grasps the identity between euphemism and common expression, which is the key to interpreting euphemism production. Interpreting euphemism production needs to seek the similarities between euphemism and common expression in different ways, focusing on how euphemism is identical to common expression. Euphemism and common expression fit in and are indistinguishable in the process of their production and accord with the principle of identity. For example:

(3) He is known to his colleagues as "Old Grape and Guts" because of his fondness for distilled refreshment. (Peter Stone and Sherman Edwards, 1776)

In (3), "distilled refreshment" is a euphemistic expression, which refers to "something distilled to refresh people". Its common expression is "wine". The euphemism "distilled refreshment" and the common expression "wine" are different in forms and meanings, but they are similar and indiscernible in terms of reference. The euphemism and the common expression together constitute the identical statement of the same thing that is not suitable to say directly.

In the view of non-reductionist physicalism, there are some differences between "type identity theory" and "token identity theory". The former holds that identity is correlation and the relation between the mental and the physical is identical as a type, while the latter holds the identity between the mental and the physical is taken from individual events or particulars of the same type (Crane, 2001, p. 52). Both "type identity theory" and "token identity theory" have their scopes and levels of application, but mostly language expresses the phenomenon of individual levels, and "token identity theory" is more widely used than "type identity theory" in language use. This also applies to euphemism production. For example:

(4) Dictating his autobiography late in life, he commented with a crushing sense of despair on man's final release from earthly struggle. (Noel Grove, Mark Twain-Mirror of America)

In (4), "man's final release from earthly struggle" is a euphemistic expression, whose common expression is "man's death". It refers to the unpleasant object "man's loss of life", corresponding to someone who is about to die, and this is a token, a special case of token under the control of the specific context and intentionality of the linguistic subject.

The basic relationship between common expression and euphemism is that they appear to be different but they are identical. Euphemism and common expression constitute the identical statement of the described unpleasant thing or event. Euphemism retains some basic content of common expression to a certain extent, but euphemism has removed some individual properties of common expression. By contrast, euphemism is more tactful or indirect than common expression.

Therefore, euphemism production highlights the linguistic subject's embodied cognition of identity with reality, which explains that euphemism is in place of common expressions to direct at the described object because euphemism is identical to common expression. The identity between euphemism and common expression is the basis of euphemism production. 


\subsection{The Embodied Cognition of Causal Implication}

The interaction between the mental and the physical follows the "principle of causal interaction" (Davidson, 1970). It is human nature to explore the causal relation between things or events, and people tend to search for the causes of all things and events that occur around them, and psychology calls this mental activity "attribution". The cause is the phenomenon before a certain phenomenon and the result, a phenomenon motivated by the cause, is the consequence of the cause. There is an implication relation between the cause and the result. Implication is a logical relation between two propositions. It usually includes substantial implication and strict implication, recorded as $\mathrm{x} \rightarrow \mathrm{y}$. Causal implication was originally put forward by Burks (1977, pp. 343-346) to discuss the thought of the causal implication in counterfactual conditionals. It is a core concept in the logic of causal statements. It refers to the causation and implication between the front and back parts of the correlated expression, and it is different from substantial implication and strict implication. Causal implication is universally applicable to human cognition. The causal implication in language use is the same as the implication in other forms of implication, but the difference lies in its causation. Causal implication has the general characteristics of logic, and causal implication inference can be summarized as follows: to establish causal implication inference, the latter part must also be false if the former part is false. For instance:

(common expression) died $\rightarrow$ (euphemism) gone to bed — but forever // not died $\rightarrow$ not gone to bed - forever

(common expression) not in the slums or ghettoes of town $\rightarrow$ (euphemism) not on the wrong side of town // in the slums or ghettoes of town $\rightarrow$ on the wrong side of town

The causal implication inference can be simply described: if $\mathrm{x} \rightarrow \mathrm{y}$, then $-\mathrm{x} \rightarrow-\mathrm{y}$, and it also has direct guidance for euphemism production. The linguistic subject can use many ways to produce euphemism, such as pun, metaphor, metonymy, and understatement, but causal implication inference is the basic means of euphemism production. Euphemism production makes use of causation and implication between euphemism and common expression to varying degrees, and there is a causal implication relationship between euphemism and common expression. To extract euphemism from the common expression must go through causal implication inference, and the cause and result of the event are also specific. For example:

(5) I want my fill of beauty before I go. (V. Sackville-West, No Signpost in the Sea)

In (5), "go" is a euphemistic expression, which is not the antonym of "come". Instead, it directs at the unpleasant event "go to heaven" or "go to a better world" and its common expression is "die". As "die" is taboo on some occasions, people will try to avoid it when talking about such a sensitive event and replace it with verbs or verb phrases, just like "go", "go to heaven" or "go to a better world". The common expression is the cause for euphemism production, and euphemism is the linguistic expression acquired through causal implication inference based on the common expression.

Thus, it can be seen that causal implication is related to the causation of specific events on that occasion, rather than abstractly considering all kinds of possibilities. The causal implication on that occasion is restricted by the context and intentionality of the linguistic subject. Sperber and Wilson (1995) holds that human cognition seeks the best relevance in cognitive context. Context is a variable, and it is the result of the linguistic subject's selection. The following example explains it very well:

(6) Mcnair: Rhode Island is out visitin' the "necessary”. (Peter Stone and Sherman Edwards, 1776)

In (6), "visitin' the 'necessary"” is a euphemistic expression. It refers to the event "there in the toilet". It is equivalent to the expression "leaving the room" in spoken language. The spoken or common expression causally implicates the euphemistic expression and their causal implication relation is restricted by the context. In other contexts, the linguistic subject can choose other euphemistic expressions such as "doing his business", "answering the call of nature", and "going to the bathroom" to refer to the event "there in the toilet".

The causal implication between euphemism and common expression is also restricted by the intentionality of the linguistic subject. Intentionality, which refers to the ability of the mind to represent the features of things or the states of events (Searle, 1983, p. 250), is characterized by representation and directionality. It includes the dimensions of intentional content (the content to be expressed) and intentional attitude (the attitude towards the expression) (Long, 2019). The intentional content of euphemism and common expression is the described unpleasant or embarrassing object. The linguistic subject chooses a common or direct intentional attitude to state the described object when using the common expression. However, the linguistic subject chooses to state the object with a tactful or indirect intentional attitude when using the euphemism. For instance:

(7) He tried soldering for two weeks with a motley band of Confederate guerrillas who diligently avoided contact with the enemy. (Noel Grove, Mark Twain-Mirror of America) 
In (7), "who diligently avoided contact with the enemy" is a euphemistic expression, which refers to the Confederate guerrillas "who were timid and reluctant to fight with the enemy". Instead of using common or direct words or phrases to describe the Confederate guerrillas, the linguistic subject uses tactful words with positive meanings, just like "diligently", to describe the Confederate guerrillas. In his opinion, the Confederate guerrillas were not inferior at all. The intentional content of the example is the Confederate guerrillas "who were timid and reluctant to fight with the enemy" and the linguistic subject takes a tactful or indirect intentional attitude towards them.

The above examples show that common expressions causally implicate euphemistic expressions, and euphemism production highlights the linguistic subject's embodied cognition of causal implication with reality, which accounts for the fact that the interaction between the mental and the physical follows the principle of causal interaction. The causal implication between common expression and euphemism is restricted by the specific contexts and the linguistic subject's intentionality.

\subsection{The Embodied Cognition of Supervenience}

Supervenience is an important concept in philosophy, which shows that the high-level things or events evolve from the low-level ones, and the properties of the high-level things or events are determined by those of low-level ones. The term "supervenience", originally coined by British ethicist Hull in the 1950s, was used to reveal the special connection between the moral and natural properties in moral ethics (Hare, 1952, p. 80). In the 1970s, Davidson published the article Mental events and the concept of supervenience was introduced to explain the relationship between the physical properties of things and the mental properties of people (Davidson, 1970, pp. 71-101). Supervenience refers to the supervenient relation between the properties of different things or events, which may exist between the physical and the physical, the physical and the mental, the mental and the mental, and the mental and the physical. If $B$ has a causal relationship with $A$, the result (A) changes with the cause (B), then A supervenes on B, and B determines A. The property of B is called the basic property, while the property of A is called the supervenient property (Kim, 1995, p. 58). The mental-physical supervenience is one of the many supervenient relationships between things or events. It is closely related to the body-mind problem, referring to the fact that the linguistic subject's cognition of the described object supervenes on his experience of the described object. Dependence and independence are the special logical relationships between high-level consciousness and low-level physical facts. Physical facts dominate and determine people's consciousness. In turn, people's consciousness both depends on physical facts and has certain autonomy. The mental-physical supervenience indicates that the supervenience of the mental on the physical must first direct at the object, and then the choice of the direction is adjusted by the intentionality of the linguistic subject.

The process of the supervenience of the mental on the physical is the one from "event" to "usage event" (Xu, 2012). "Event" refers to any natural or social event, and "usage event" is the symbolic expression constructed by the linguistic subject based on his subjective knowledge (Langacker, 2004, p. 66). Event is the cause of usage event and usage event is based on the result of the event. Event causally implicates usage event and they together present a nonlinear causal implication relation. The same event can lead to different usage events because different people may adopt different ways of conceptualization. The nonlinear causal implication between event and usage event results in linguistic diversities. For example:

(8) Franklin: we'll be long gone. (Peter Stone and Sherman Edwards, 1776)

In (8), "be long gone" is a euphemistic expression, which refers to the event "disappear from the earth". The common expression "be dead" is a direct description of the event, reflecting the experience of the described event, i.e., being unpleasant. The euphemistic expression represents the linguistic subject's cognition of the event There is a non-linear causal implication relation between the common expression and the euphemistic one. As the usage event, the euphemistic expression is event-dependent, restricted by the specific context and the intentionality of the linguistic subject.

From the viewpoint of cognitive psychology, the process from "event" to "usage event" is one from perception to feeling $(\mathrm{Xu}, 2016)$. The linguistic subject uses his sensory organs to obtain the perception of the described thing or event, indicating the conventionalized meaning of the linguistic expression and its logical structure. However, the feelings of the linguistic subject towards the described thing or event show how the thing or event will be represented according to the specific context and the intentionality of the linguistic subject. As the previous examples reveal, the linguistic subject may have a variety of feelings towards the same physical event such as "disappear from the earth", so its euphemisms are abundant. These euphemisms reflect the pluralistic cognition and different feelings of the linguistic subject towards the described event "disappear from the earth". Euphemism production is the result of the emergence of the linguistic subject's consciousness. 
Besides, the research findings of supervenience show that if the context and the free will of the linguistic subject are taken into account, there will be strong and weak supervenience. Kim (1995) also uses indiscernibility in defining supervenience and classifies supervenience into weak, strong, and global supervenience.

"A weakly supervenes on B if and only if necessarily for any $\mathrm{x}$ and $\mathrm{y}$ if $\mathrm{x}$ and $\mathrm{y}$ share all properties in $\mathrm{B}$ then $\mathrm{x}$ and $\mathrm{y}$ share all properties in $\mathrm{A}$ - that is, indiscernibility with respect to $\mathrm{B}$ entails indiscernibility with respect to A". (Kim, 1995, p. 58)

"A strongly supervenes on B just in case, necessarily, for each $\mathrm{x}$ and each property $\mathrm{F}$ in $\mathrm{A}$, if $\mathrm{x}$ has $\mathrm{F}$, then there is a property $\mathrm{G}$ in $\mathrm{B}$ such that $\mathrm{x}$ has $\mathrm{G}$, and necessarily if any y has G, it has F". (Kim, 1995, p. 65)

"A globally supervenes on B just in case worlds that are indiscernible with respect to B (B-indiscernible, for short) are also A-indiscernible". (Kim, 1995, p. 68)

Strong supervenience entails weak supervenience, but weak supervenience does not entail strong supervenience (Kim, 1995, p. 67). Of these three kinds of supervenience, global supervenience is the weakest. Weak and strong supervenience are reducible and their typical context is the multi-world domain. Global supervenience is irreducible, and its typical context is the single-world domain (Chen, 2010). Euphemism production, which includes different levels of consciousness and the linguistic subject's embodied cognition with reality, occurs in the single-world domain. The high-level consciousness of the linguistic subject towards the described thing or event supervenes globally on its low-level physical property. Euphemism production highlights the linguistic subject's embodied cognition of the mental-physical supervenience.

\section{Conclusion}

Euphemism, a common linguistic phenomenon in English, Chinese, and many other languages, is a substitution expression. Substitution is its inherent nature and euphemism production takes on the substitution nature. This paper takes the euphemisms in English literary works as the corpora and explores the cognitive prominence of euphemism production from the perspective of the embodied-cognitive approach to reveal the production mechanism of euphemism. The research findings indicate that the linguistic subject's embodied cognition of identity, causal implication, and supervenience with reality is prominent in euphemism production. Euphemism production is the result of the linguistic subject's embodied cognition with reality. Besides euphemism, metaphor, metonymy, personification, irony, and hyperbole also take on the substitution nature in their production, and cognitive prominence from the perspective of the embodied-cognitive approach also has very strong explanatory power over their production mechanism.

\section{Acknowledgement}

This research was supported by "The 13th Five-Year Plan" Project of Social Science Research in Sichuan Province (A Foreign Language Program) (Grant Number: SC19WY026)-Research on the Professional Development of Foreign Language Teachers in Local Undergraduate Universities from the Perspective of Socio-Cultural Theory.

There is no conflict of interest to publish this paper in this Journal.

\section{References}

Burks, A. W. (1977). Chance, Cause, Reason. Chicago: The University of Chicago Press.

Chen, X. P. (2010). Concepts of "Supervenience" and Their Philosophical Implication-Comments on Kim's Theory of Supervenience. Studies in Philosophy of Science and Technology, 27(4), 1-8.

Crane, T. (2001). Elements of Mind: An Introduction to the Philosophy of Mind. Oxford: Oxford University Press.

Davidson, D. (1970). Mental Events in Foster. In L. Foster \& J. W. Swanson (Eds.), Experience and Theory (pp. 71-101). Amhert: University of Massachusetts Press.

Diez-Arroyo, M. (2016). English Words as Euphemisms in Spanish Fashion. English Today, 32(3), 30-39. https://doi.org/10.1017/S0266078416000043

Hare, H. M. (1952). The Language of Morals. Oxford: Clarendon Press.

Kim, J. (1995). Supervenience and Mind: Selected Philosophical Essays. Cambridge: Cambridge University Press.

Langacker, R. (2004). Foundations of Cognitive Grammar (Volume 1). Beijing: Beijing University Press.

Lei, Q. (2019). Denotations and Connotations of Generic Sentences: A Perspective from an Embodied-Cognitive 
Approach. Foreign Languages in China, 16(6), 44-49.

Leibniz, G. W. (1969). Philosophical Papers and Letters. Dordrecht: D. Reidel Press.

Li, K. (2016). The Intentionality Study of Euphemism. Foreign Language Research, 2, 83-87.

Li, W. H. (2002). A Socio-Cultural Perspective of English and Chinese euphemisms. Journal of Fuzhou University (Philosophy and Social Sciences), 1, 57-60.

Linfoot-Ham, K. (2005). The Linguistics of Euphemism: A Diachronic Study of Euphemism Formation. Journal of Language and Linguistics, 2, 227-263.

Liu, C. B. (2002). English Euphemism Dictionary. Beijing: The Commercial Press.

Liu. Q. (2013). A New Study of Euphemistic Expression: A Philosophy-of-Mind Approach to Language. Kaifeng: a doctoral dissertation presented to Henan University.

Long, D. Y. (2019). An Exploration of the Topological Nature of Chinese Simulating Shape Utterance. Foreign Studies, 7(3), 19-24.

Peng, Z. B. (2019). Further Exploration of Postmodern Philosophical Origin in Embodied-Cognitive Linguistics. Foreign Language and Literature, 5, 30-37.

Searle, J. (1983). Intentionality: An Essay in the Philosophy of Mind. Cambridge: Cambridge University Press. https://doi.org/10.1017/CBO9781139173452

Sperber, D., \& Wilson, D. (1995). Relevance: Communication and Cognition. Oxford: Blackwell.

Ungerer, F., \& Schmid, H. J. (2001). An Introduction to Cognitive Linguistics. Beijing: Foreign Language Teaching and Research Press.

Wang, W. B., \& Liu, G. (2020). A Cognitive Profiling Perspective on the Verbal Nature of Many English Nouns from PIE roots. Foreign Language Teaching and Research, 2, 163-175, 319.

Wang, Y. (2006). An Introduction to Cognitive Grammar. Shanghai: Shanghai Foreign Language Education Press.

Wang, Y. (2014). Embodied-Cognitive Linguistics in the View of Postmodernism. Foreign Language and Literature, 6, 61-67.

Wang, Y. (2019). An Analysis of Embodied-Cognitive Linguistics from Philosophy of Language. Foreign Language Research, 3, 26-30.

Xu, S. H. (2012). From Event to Usage Event: The Forming of the Initial Shape of Sentence Representation. Journal of Henan University (Social Science), 52(4), 137-144.

Xu, S. H. (2015). Causal Implication and the Generating of Tactful Speech. Foreign Language Teaching and Research, 3, 323-332, 479.

Xu, S. H. (2016). Implied-meaning Thinking: Approached from the Perspective of Mind. Foreign Language Research, 1, 11-17, 32 .

\section{Copyrights}

Copyright for this article is retained by the author, with first publication rights granted to the journal.

This is an open-access article distributed under the terms and conditions of the Creative Commons Attribution license (http://creativecommons.org/licenses/by/4.0/). 